\title{
Acceptability of innovative biomass heating plants in a German case study-a contribution to cultural landscape management and local energy supply
}

\author{
Maria Busse $^{1 *} \mathbb{D}$, Rosemarie Siebert ${ }^{1}$ and Nico Heitepriem ${ }^{2}$
}

\begin{abstract}
Background: To prevent negative effects on the cultural landscape through land abandonment or agricultural intensification, innovative solutions towards more sustainable land use are required. Local bioenergy systems using agricultural co-products are perceived as one solution to threatened cultural landscapes with small-scale meadows. The aim of this paper is to analyse the acceptability of biomass heating plants in the Spreewald region (Germany) and their contribution to cultural landscape management.

Methods: We asked 17 farmers about the likelihood that they would install a biomass plant on their farms and about their reasons for accepting or rejecting it. A fuzzy set qualitative comparative analysis was applied.

Results: The analysis showed that acceptance is relatively low. We identified three types of farmers: proponents and potential adopters, ethically concerned opponents, and open-minded refusers. Biomass plants were likely to be accepted if farmers stated an ethical acceptance of and interest in technology, a need for a new heating system, the availability of sufficient feedstock, and a perceived unproblematic readiness of technology - all these factors had to exist in combination. On the other hand, farmers rejected a biomass plant if one of the following factors existed: ethical concerns about "burning hay", satisfaction with their current oven, low availability of feedstock, or a perceived low readiness of technology. Other factors were the existence of procedural justice, trust in coordinating actors, and a demonstration plant.
\end{abstract}

Conclusions: The discussion shows that the specific results have to be contextualised within the innovation process for sustainable landscape management. This may be achieved by integrating the acceptability study into an adaptive landscape design. This relies on mutable acceptability decisions, reflexive learning processes, and iterative feedback loops in innovation processes. Our paper advances knowledge about (1) how to prevent land abandonment and simultaneously promote regional energy and (2) the acceptability in the field of land use and landscape management.

Keywords: Fuzzy set qualitative comparative analysis (fsQCA); Bioenergy; Energy transitions; Co-products; Biomass conversion; Gasification; Land abandonment; Wetlands; Integrative landscape design

\footnotetext{
* Correspondence: maria.busse@zalf.de

${ }^{1}$ Leibniz Centre for Agricultural Landscape Research (ZALF), Eberswalder Str.

84, 15374 Müncheberg, Germany

Full list of author information is available at the end of the article
}

(c) The Author(s). 2019 Open Access This article is distributed under the terms of the Creative Commons Attribution 4.0 International License (http://creativecommons.org/licenses/by/4.0/), which permits unrestricted use, distribution, and reproduction in any medium, provided you give appropriate credit to the original author(s) and the source, provide a link to the Creative Commons license, and indicate if changes were made. 


\section{Highlights}

- Local biomass plants could prevent land abandonment in cultural landscapes.

- Local biomass plants could promote regional energy supply.

- QCA revealed three farmer types regarding their of biomass plants.

- Low acceptance of biomass plants at the farm level due to various conditions.

- Need to integrate acceptability studies into adaptive landscape design.

\section{Background}

Currently, most cultural landscapes worldwide are mainly confronted with land use changes and, therefore, with two opposing problems: intensification of agricultural production or land abandonment [1-3]. Whereas some cultural landscapes are threatened by cost-efficient and intensive agriculture, in other landscapes, the importance of agricultural production is shrinking. The land abandonment scenario mainly takes place in cultural landscapes that have diverse and small structures and that are often difficult to access, such as mountain regions [1], upland pastures [4], and terraced landscapes or wetlands [5]. The cultivation of such landscapes is perceived as no longer economically viable due to its cost intensity [6-8]. Both problematic situations-land abandonment and agricultural intensification-can dramatically decrease the functioning of the ecosystem, biodiversity, and cultural values [2, 7-10].

At the same time, in the last decades, there has been a rising demand for bioenergy from landscapes $[6,7]$. Bioenergy, especially that from energy crop production, is directly linked to agricultural intensification and risks causing the abovementioned ecological and social impairments [11]. Thus, in the meanwhile, bioenergy is viewed more critically and is under pressure to prove its longterm benefits for a sustainable development of agricultural landscapes and for renewable energy transitions $[6,12$, 13]. A challenge is to harmonise bioenergy production with other uses, such as food production, by considering its trade-offs. The trade-offs of bioenergy production are addressed by various Sustainable Development Goals (SDGs 2, 7, 13, 15) and, for instance, are expressed in the "food-fuel debate" $[11,14,15]$. To prevent and counter the negative effects of land abandonment and agricultural intensification through bioenergy production, innovative solutions towards more sustainable land use are required. These solutions have to be site-specific and adapted to the setting of each landscape. Bioenergy ${ }^{1}$ systems that use residuals, "surplus" grassland biomass, and agricultural co-

\footnotetext{
${ }^{1}$ Bioenergy is renewable energy made from materials derived from biological and, thus, non-fossil sources ([14], cf. [15]).
}

products have the potential to address such risks $[6,7$, 13]. They are perceived as one solution for formally used cultural landscapes that are composed of grasslands or meadows and are now increasingly under threat of falling out of use. Hence, this innovative use of residuals for bioenergy production can potentially contribute to both suitable cultural landscape management and a decentralised energy supply. In particular, decentralisation is an important topic in recent energy transition debates all over the world [16]. The regional level is seen as decisive for the success of national energy transitions, such as the "German Energiewende" [17, 18]. Furthermore, the exploitation of biomass has some advantages in moving forward renewable energies, such as the better possibilities of energy storage and the opportunity of economic development for rural areas [19].

The issue of using biomass from residuals is of rising interest in science. In the scientific literature, the current research focus is on technological aspects, such as efficiency and reducing emissions of conversion technologies [20]. Some research exists on the residual feedstock characteristic for the gasification process [21] and for producing biogas [22]. A sustainability assessment of different bioenergy technologies (including gasification of landscape material) has been conducted by Grunwald and Rösch [6] Socio-economic studies deal mainly with feedstock availability and the willingness to supply straw for bioenergy production $[23,24]$ and the acceptability aspects of biofuel and biogas production [25-27]. However, there is a research gap concerning knowledge about the acceptability and socio-technological interactions of local biomass plants using agricultural residuals. The issue of acceptability should be addressed as early as possible in the innovation process. Only in cases where local actors accept the innovative idea as a solution to land abandonment and want to implement this technology is it worth continued promotion of the innovation process. As high acceptance is a success factor for implementation in general, analysis of acceptability and the identification of potentials or implications for further adoption at the local level must be done. Furthermore, it is worth gaining knowledge about the potential contribution of local bioenergy plants to maintaining cultural landscapes and promoting energy transitions.

The present case study aims to contribute to this research gap by investigating the potential of bioenergy from residuals as part of the solution to unused wetland meadows in the cultural landscape of the Spreewald region (Germany). The specific aim of this paper is to analyse the acceptability of biomass heating plants by farmers of the case study region. In this context, farmers are crucial actors because one of their possible roles is to implement a biomass plant on their farms. Our guiding research questions are as follows: 
RQ1: Which conditions (other than the need for financial support) influence the decisions of local farmers to accept or reject on-farm biomass plants?

RQ2: Which pathways lead to acceptance, and which lead to rejection?

RQ3: What conclusions can be drawn for regional landscape design and management?

\section{Theoretical framework}

Theories typically used when dealing with the acceptability of (technical) innovations are the Diffusion of innovation (DOI) theory by Rogers 1995 and the Technology acceptance model (TAM) by Davis [28] (cf. [25]). From a more sociological and innovation-system perspective, both theories have their shortcomings concerning the extent to which they are technology-driven, the deterministic character of their stages and factors, and their neglect of interwoven socially constructed processes and systems [29, 30]. Mallett [30] critically points out that Rogers' adopter categories (innovators, early adopters, early and late majority, and laggards) and communication principles are described in a reductionist manner, ignoring complex and multiple interactions and communication flows between actors, social norms, or institutional settings. Thus, there is a need for a framework that considers acceptability as a complex phenomenon that includes openness for different explanatory factors and links to socio-technical systems. Due to this, we apply the sociological-driven, processoriented, and open understanding of acceptability as suggested by Busse and Siebert [25]. The authors define acceptability as a bundle of complex, non-static but mutable decision processes regarding a certain object made by different involved actors. These processes are characterised by the use of value-based arguments and by different acceptability degrees-ranging from rejection to high acceptance or even engagement. According to this understanding, acceptability and acceptance are not synonyms. Acceptance is a positive outcome of a decision process. Within this process, an active reflection on the issue within its context and interaction with others and social norms are required [25]. Acceptability studies should involve context factors, such as institutional settings and fairness of the process, system thinking, and the consideration of socio-technical regimes [16]. The present paper focuses on the acceptability decisions that are made by farmers at an early stage in the innovation process (cf. the next section on the case study description). Thus, we observe only one (but important) piece of a puzzle-the complex acceptability phenomenon.

Considering the concept of social acceptance by Wüstenhagen et al. [31], our analysis is mainly covered by the type "market acceptance", which is defined as the "process of market adoption of an innovation". At the same time, market acceptance is more than a mere market-based assessment by farmers. Due to its relation to visions of landscape development and conservation, market acceptance also contains elements of "community acceptance", where opinions and judgements of local stakeholders and end users on site-specific renewable energy projects and institutional settings play a major role [16, 31]. Regarding the acceptability degrees, we want to pay special attention to temporary and inconclusive decisions, the so-called doubt or conditional acceptance [32], and to "rejection" or "non-use" of innovations $[25,33]$. When analysing acceptability, most researchers focus only on the positive outcomeacceptance-while neglecting the negative degrees. "It is taken as given that novel technologies diffuse from innovators to the mass market - a transfer in which non-use is thought to disappear over time" [33]. However, we can learn a lot from motivations or conditions that cause rejection.

\section{Case study description and methods Case study description}

The Spreewald region is located in Eastern Germany (see Fig. 1). This historically grown cultural landscape is characterised by an extended network of natural streams (the main river Spree and its side arms) and artificial water channels. The small-scale cultural landscape is composed of different types of wetland meadows and forests and arable farmland. The case study area is part of the Biosphere Reserve Spreewald. As mentioned in the introduction, the Spreewald is affected by land abandonment, especially the small-scale wetland meadows, which are increasingly under threat of falling out of use due to economic, cultivation-related, and water management reasons. Some parts of the wetlands are already overgrown with sedges (Carex acuta L., Carex acutiformis Erh.), common reed (Phragmites australis), grey willow (Salix cinerea), black alder (Alnus glutinosa), and other common species.

Land abandonment can be seen as problematic for at least three reasons: (1) formerly sustainable used wetland meadows are increasingly abandoned; 2 ) the biodiversity of these wetlands, of which preservation is (in parts) legally binding, is decreasing (e.g. species and habitats protected by the European Habitats Directive); and (3) the typical character of the open landscape and, therefore, a particularly important part of the regional cultural heritage and identity is threatened.

For these reasons, regional key actors (mainly, the non-profit foundation for the cultural landscapes in the Spreewald region-Bürgerstiftung Kulturlandschaft Spreewald-and the Biosphere Reserve Spreewald authority) recently aimed to develop an innovative strategy to reuse and maintain the wetland meadows. One 


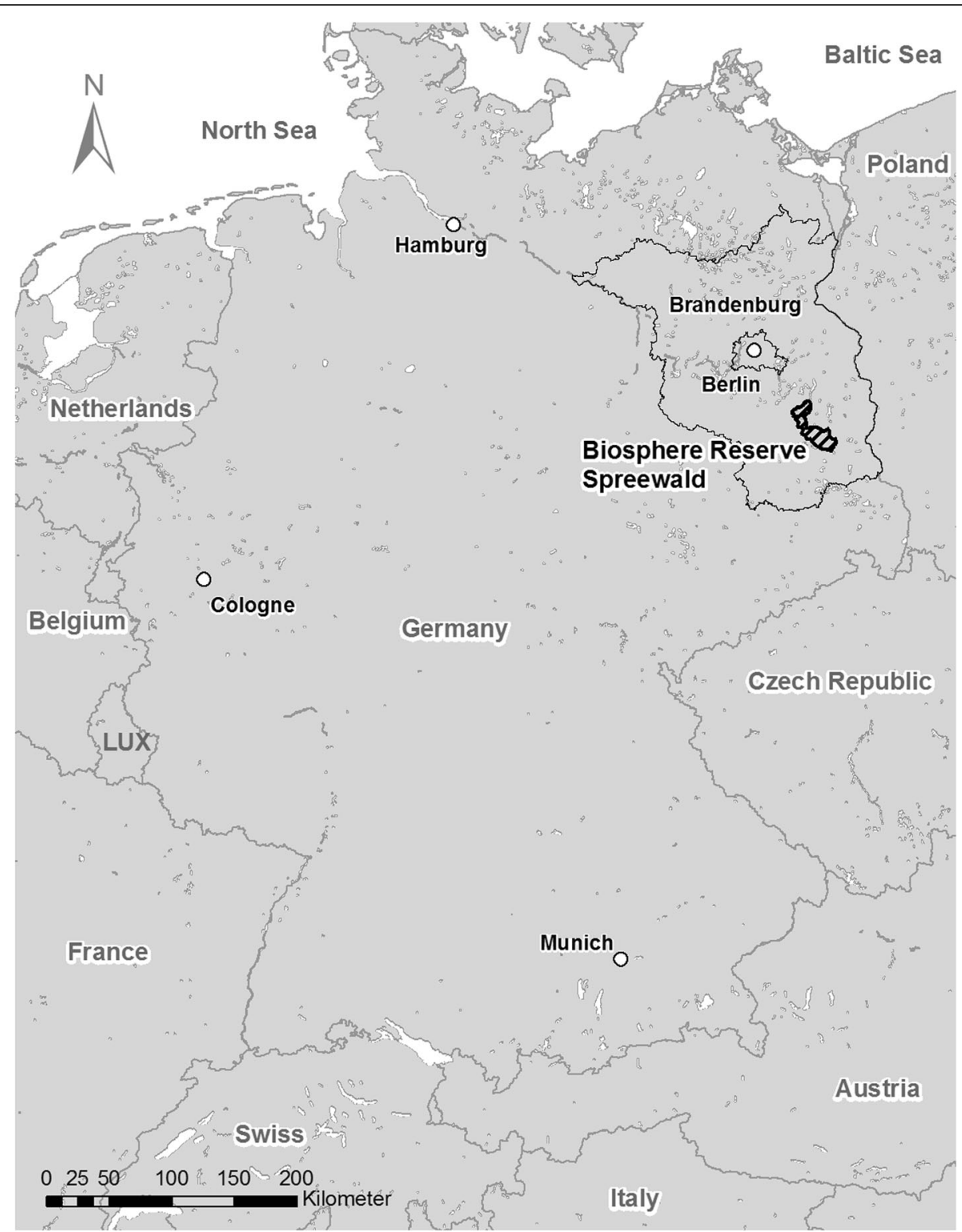

Fig. 1 Location of the Biosphere Reserve Spreewald in Germany. The biosphere reserve is the core of the Spreewald region

part of this landscape strategy encompasses the idea to use biomass from wetland meadows to generate heat at the local level. The idea of using the wetlands' biomass is not a new one in this region. For 20 years, the region has addressed wetland abandonment by experimenting with biogas production without great success. One reason was that the biomass from the wetlands is very heterogeneous and has a high lignin content resulting in a low biogas yield. This failure caused scepticism and resignation among the involved regional actors (Expert 1-3, Additional file 1). For a few years, gasification technology has been brought into play. Gasification, like combustion and pyrolysis, is a thermos-chemical conversion technology applied to biomass [34] (Fig. 2). Since 2016, a pilot biomass plant (generating $200 \mathrm{~kW}$ ) has operated on a farm in the Spreewald to test the technology and practical procedures (Fig. 3). The latter includes the production and logistics of the feedstock, operational integration of heat production into the daily work on the farm, efficiency, cost calculation, emissions, and co-products (ashes). The implementation of this demonstration plant was a collaborative achievement by a transdisciplinary project that started in 2014. The project is the collaboration between regional key actors from different sectors (nature conservation, tourism, agriculture, and civic society) and social and agricultural scientists. 


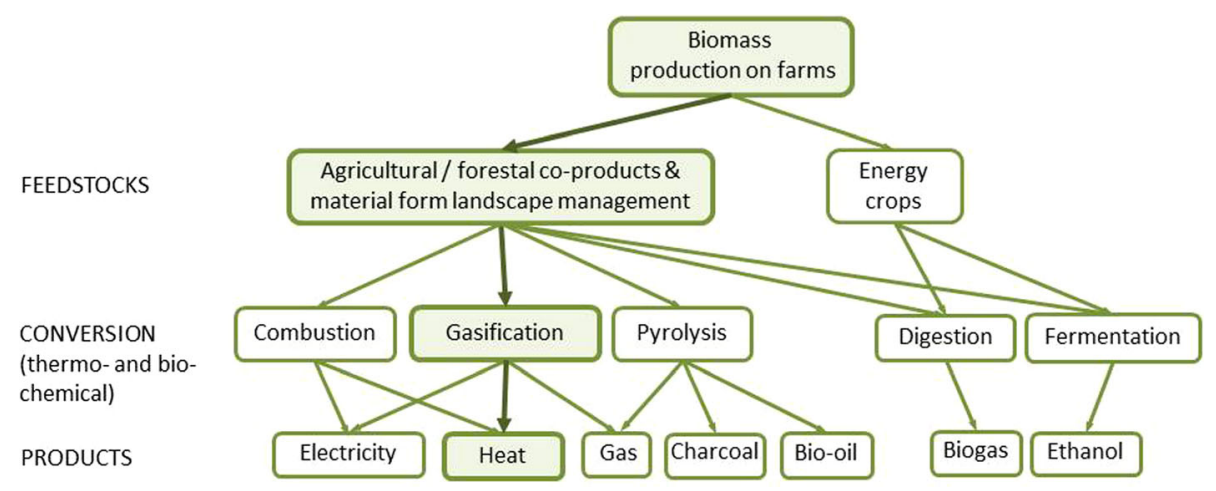

Fig. 2 Bioenergy systematisation (adopted by McKendry [34] and Arbolino et al. [19]). Fields and arrows in bold are relevant for the present case study

The technology used follows a two-step gasification process (Fig. 3). First, in the hay carburettor chamber, the biomass from wetlands is gasified. In a second step, the after-burner heat exchanger converts gas into thermal energy. Such plants are available in different sizes (from approximately 50 - to $10,000-\mathrm{kW}$ plants) and types. The advantages of this technology are its highlevel efficiency and low rate of emissions. The different steps carried out by farmers for generating and using the heat produced by such biomass plants are illustrated in Fig. 4. The technology is quite new and not yet broadly applied to biomass from marginal landscapes in practice.

\section{Methods}

The acceptability of biomass heating plants by local farmers is a complex research issue embedded in a reallife context and carries many unknown aspects. Addressing adequately this initial condition, we chose a qualitative research approach [35] with an embedded case design [36]. The main part of the research design consists of qualitative comparative analysis (QCA) [37-39]. With QCA, we were able to unravel configurational patterns for acceptance and rejection and to create a typology of farmer groups [38]. An additional reason for choosing QCA was that it is a suitable method for middle-sized datasets with approximately 10 to 50 cases [37].

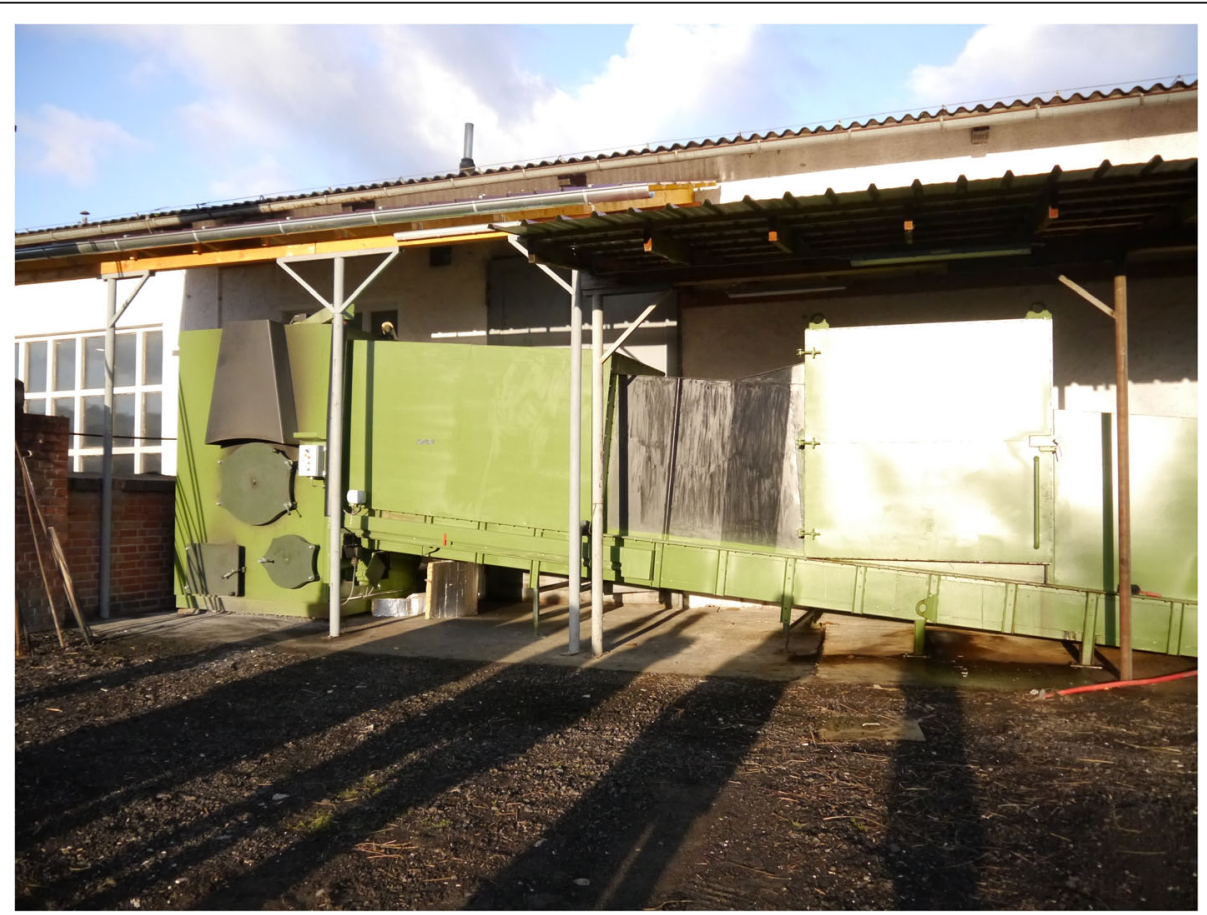

Fig. 3 Pilot project of the biomass gasification plant in the Spreewald region 


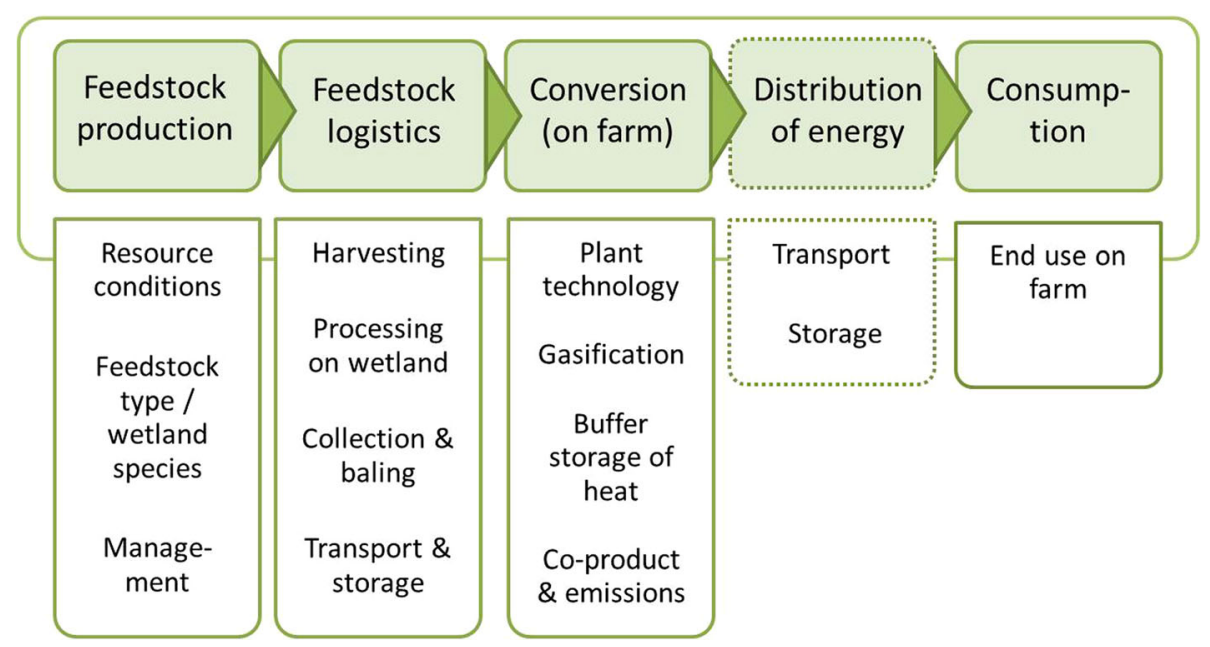

Fig. 4 Bioenergy supply system with production stages of generating and using heat from on-farm biomass. Distribution is only required in the case of collective or community power plants (adopted by Dale et al. [14])

Generally, in QCAs, values are classified into the so-called sets, which will be placed in relation to each other. QCA is a set-theoretic technique that aims at revealing configurational pathways that lead to the specific phenomenon-the so-called outcome. The pathways consist of singular conditions or a pattern of conditions. Thus, causal relations for phenomena can be described using the concepts of equifinality ${ }^{2}$ and asymmetry ${ }^{3}$. We applied the fuzzy set QCA variant (fsQCA), with which "differences in the degree of set membership can be captured" [38]. FsQCA is recommended for analysis because it contains more information than dichotomous crisp sets [38]. The identification of necessary and sufficient conditions from a set of variables is crucial for QCAs. To better comprehend our results, it is important to understand these basic elements of each QCA. Necessary conditions are defined by the following statement: Wherever a certain outcome is present, condition A is also present. For example, a necessary condition means that all interviewees who accepted an idea (positive outcome) also had to have an interest in this topic (condition A). Condition B is a sufficient condition if wherever condition B is present, a certain outcome is also present. For instance, all interviewees who had ethical concerns (condition B) also rejected the idea (negative outcome). At the same time, other sufficient conditions can also lead to rejection [38].

\footnotetext{
${ }^{2}$ Equifinality in set theory means multiple conditions (or a combination thereof) co-exist to describe the same outcome [37].

${ }^{3}$ Asymmetry in set theory means that explanations for a positive outcome cannot be derived automatically from the explanation for the negative outcome [37].
}

\section{Data collection}

In 2015 and 2016, nine explorative interviews were conducted to identify important conditions influencing acceptability of biomass plants by farmers. This step was also necessary to familiarise ourselves with the issue. Among the interviewees are three regional experts and six regional farmers. The latter group includes the farmer who built the regional pilot plant. Additionally, two expert group discussions with regional experts (including the pilot plant owner), the innovator (oven constructer), and scientists were held in 2016. The group discussions allowed us to understand the advantages and disadvantages of implementing the technology in the Spreewald region and to identify conditions influencing acceptability from an expert perspective. Both interview results and insight from the group discussions were used to design a standardised questionnaire with the aim of performing surveys for the fsQCA. The questionnaire contained general information about the farms and production characteristics and questions about the likelihood of implementing a biomass plant on the farm (outcome question for the QCA), the conditions that influenced the farmers' decisions (e.g. ethical aspects, costs, technological and operational aspects, fairness and communication), alternative solutions, and the farmers' interest in maintaining the cultural landscape (Additional file 2). We formulated mainly closed questions with prefixed items (using a 4-point Likert scale). Additionally, the possibility of adding detailed statements was given.

In spring 2018, 17 face-to-face interviews with farmers of the Spreewald region were conducted using the previously described questionnaire. During the interview, the first author of this paper filled in the questionnaire (according to the farmer's answers) and wrote down the 
Table 1 Membership scores for outcome of interest and variables (similar to 4-point scale in questionnaire)

\begin{tabular}{lll}
\hline Membership scores & Outcome of interest & Items \\
\hline 0 & Extremely unlikely implementation, rejection & I completely disagree. \\
0.3 & Unlikely implementation & I mostly disagree. \\
0.5 & Neither acceptance nor rejection* & Neither agree nor disagree* \\
0.7 & Rather likely implementation & I mostly agree. \\
1 & Very likely implementation, acceptance & I completely agree. \\
\hline
\end{tabular}

*Items are not used in the questionnaire but have to be defined as qualitative anchor according to the QCA rules

farmers' additional statements. In most cases, interviewees gave permission to record the interviews. Directly after the interviews, notes about the interview situation were taken and further information was gathered to support the information value of the interviews. Thus, a transcription of the interviews from the second phase of interviews in 2018 was not necessary (Additional file 1: interview list).

\section{Data processing and analysis}

Data processing encompassed the development of a codebook based on the questionnaire and survey data entry into an Excel database. A comparison with the recorded audio file of each interview was made to clarify vagueness or any misunderstanding in the survey data. This step of back-checking guarantees that farmers' selfjudgements on the Likert scale represents a realist picture of their attitudes. Thus, it serves as qualitative validation of the coded items. Defining the outcome of interest, the potential influencing variables, and the qualitative anchors for identifying the membership scores (for outcome and variables) is obligatory when using the QCA method [38]. The qualitative anchors and membership scores were predefined through 4-point Likert scales in the questionnaire (Table 1). Due to including the farmers' self-judgement regarding outcome of interest and variables, a calibration of raw data by the researchers was not necessary. The farmers' self-judgements were taken as QCA membership scores.

The questionnaire contained a very large number of possible variables for the QCA (see Additional file 2), but only five variables were finally used for the analysis. These selected variables are displayed in Table 2. The process of reducing variables is in line with the methodological literature. ${ }^{4}$ The decision fell on these five variables because they were determined to be the most

\footnotetext{
${ }^{4}$ Schneider and Wagemann [38] recommend a moderate number of variables for QCAs to decrease the number of possible condition combinations and to avoid a long list of logical remainders. They state (p. 276f) that approximately $3-5$ variables in a study with $20-40$ cases are suitable. For the reduction process, we iteratively balanced between empirical insights and our prior theoretical knowledge. As recommended by Schneider and Wagemann [38], we created a macrovariable ("Ethical acceptance") as a reduction strategy.
}

important for farmers when making a judgement about their attitude. ${ }^{5}$ Afterwards, the selection of variables was back-checked with our knowledge that went beyond the QCA data (mainly from the group discussion because there is no information from literature available). ${ }^{6}$ The "need for financial support" was excluded from the analysis of necessary and sufficient conditions for acceptance and rejection. All interviewees stated that they would need financial support regardless they accept or reject the implementation of a biomass plant. Thus, the influence of this condition is negligible for analysis outcome. This phenomenon is called "trivial condition" which should be excluded from interpretation [38]. However, the "need for financial support" can be seen as a basic and essential precondition.

The fuzzy set data were analysed using the software fsQCA 2.5 by Charles Ragin. Comprehending QCA and reproducing our results are crucial to knowing the basic operations of Boolean and fuzzy algebra and quality check instruments for QCAs as they are displayed in Table 3.

As usual in QCAs, first, we analysed the necessary conditions for the positive outcome (=acceptance) and negative outcome (= rejection). Afterwards, the sufficient conditions were identified. For the analysis of sufficient conditions, we displayed our empirical evidence in the so-called truth tables (Additional files 4 and 6), as recommended by Schneider and Wagemann [38]. Generally, truth tables contain all logically possible combinations of variables and their respective outcome values observed in the analysed cases. Each row stands for one combination of variables.

\footnotetext{
${ }^{5}$ The interview material showed that questions about other variables could not be easily answered by farmers at this stage, with their knowledge regarding the technology and the consequences for implementation. These variables become important for farmers who are already willing to implement a biomass plant and think in detail about implementation consequences.

${ }^{6}$ Theoretical knowledge from literature could not be used to select conditions because there are no published studies about the acceptability of local biomass plants (using gasification of hay) by farmers. It is a very new issue. Factors influencing acceptability from somewhat related topics are not useful because factors vary from case to case (and research question to research question). Therefore, we used this explorative procedure.
} 
Table 2 Variables included in fsQCA

\begin{tabular}{|c|c|c|}
\hline Variables & Variable name* & Variable sources \\
\hline Ethical acceptance & ETHICS/ethics & $\begin{array}{l}\text { Macro variable, mean of four sub-variables: (1) acceptance of } \\
\text { using biomass for generating heat and (2) its usefulness, (3) } \\
\text { relevance for local energy supply, and (4) relevance for } \\
\text { maintaining regional wetlands }\end{array}$ \\
\hline General interest in specific carburettor technology & INTEREST/interest & Survey data directly used \\
\hline $\begin{array}{l}\text { Insufficient readiness of technology as perceived } \\
\text { implementation barrier }\end{array}$ & $\begin{array}{l}\text { READYBARRIER/ } \\
\text { readybarrier }\end{array}$ & $\begin{array}{l}\text { New built variable using data from variable "interest in } \\
\text { technology" and "perceived readiness of technology" } \\
\text { (code plan: Additional file 3) }\end{array}$ \\
\hline Satisfaction with current heating system on farm & SATISF/satisf & Survey data directly used \\
\hline No availability of material (feedstock) & NOMAT/nomat & Survey data directly used \\
\hline
\end{tabular}

*For explanation see Table 3

Consulting the truth tables, we decided on logical remainders (rows with no empirical evidence) and excluded them from minimisation. In the minimisation process, row information is summarised to extract the final solution term of sufficient conditions by applying fuzzy algebra [38].

\section{Results}

To gather the outcome values for the QCA, the farmers were asked how likely they were to install a biomass heating plant on their farm within the next 5 years. This information served us as proxy for identifying the acceptability decision degrees (acceptance or rejection).

Among the 17 interviewed farmers, 13 stated that it is "extremely unlikely" or "unlikely" that they will implement such a biomass plant on their farms. Only four farmers responded that implementation is "rather likely" or "very likely" (see Fig. 5).
Clustering the cases according to the outcome (acceptance or rejection) and underlying conditions, we found three types of farmers:

A) Proponents and potential adopters

B) Ethically concerned opponents

C) Open-minded refusers

In the following, these farmer types will be described in detail.

\section{Acceptance cases-“type A" farmer}

The "type A" farmers can be labelled as proponents of the technology and potential adopters. The underlying conditions show that none of the conditions is a relevant necessary condition for acceptance. Table 4 displays that three single conditions (ETHICS, INTEREST, readybarrier) and all combinations of conditions passed the consistency test, in which a consistency threshold above 0.9 is recommended by Schneider and Wagemann [38].

Table 3 Basic operations in Boolean/fuzzy algebra and definitions of quality check instruments, according to [38]

\begin{tabular}{|c|c|}
\hline Operations and terms & Definition \\
\hline * & Logical AND \\
\hline+ & Logical OR \\
\hline Outcome in upper-case letters $(Y)$ & Positive outcome (= acceptance) \\
\hline Outcome in lower-case letters (y) & Negative outcome (= rejection) \\
\hline Condition in upper-case letters (e.g. INTEREST) & Condition is present. \\
\hline Condition in lower-case letters (e.g. interest) & Condition is absent. \\
\hline Consistency of necessary or sufficient condition & Degree of data being in line with statement of necessity or sufficiency. \\
\hline Coverage of necessary condition & Relevance measure of necessary condition; coverage within the set of all cases. \\
\hline Raw coverage of sufficient conditions & Degree to which outcome is covered by a statement. \\
\hline Unique coverage of sufficient conditions & Degree to which outcome is UNIQUELY covered by a statement. \\
\hline Solution coverage & Degree to which outcome is covered by the all pathways/entire solution term. \\
\hline Logical remainder & A possible logical combination without empirical evidence. \\
\hline Conservative solution term & Solution term without assumption about logical remainders. \\
\hline
\end{tabular}




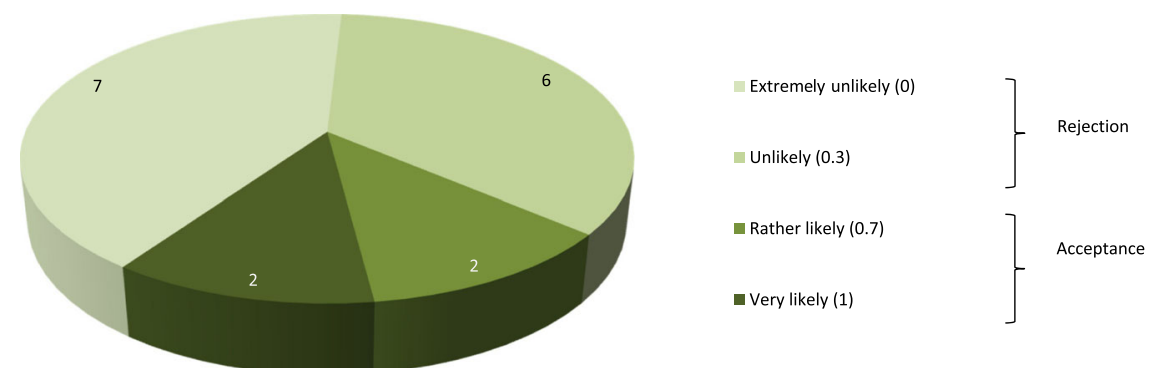

Fig. 5 Likelihood of implementing a biomass plant on farm as proxy for acceptability decision degree

However, none of the tested necessary conditions shows a higher coverage value than 0.5 .

The results of the analysis of sufficient conditions show that only when all five tested conditions are met in a single case does a farmer state that he is likely to implement a biomass plant on his farm. A farmer in this group (1) ethically accepts the idea to use a biomass plant for the maintenance of wetland meadows and supplying local energy, (2) is generally interested in the technology, (3) does not perceive the low readiness of the technology as a barrier, (4) is not satisfied with the current heating system on his farm, and (5) has feedstock for the biomass plant available on his farm. These sufficient conditions for acceptance can be described by the following conservative solution term ${ }^{7}$ (based on the truth table in Additional file 4):

ETHICS"INTEREST"readybarrier"satisf"nomat

\footnotetext{
${ }^{7}$ The parsimonious solution term (the at least complex solution term) for acceptance is "satisf"nomat" (solution coverage 0.769, solution consistency 0.818). The intermediate solution term for acceptance that included easy counterfactuals is "ETHICS"readybarrier"satisf"nomat" (solution coverage 0.769 , solution consistency 0.816 ).
}

Table 4 Necessary conditions for acceptance (Y)

\begin{tabular}{lll}
\hline Conditions tested & Consistency & Coverage \\
\hline ETHICS & 1.000 & 0.371 \\
INTEREST & 1.000 & 0.481 \\
readybarrier & 0.942 & 0.418 \\
satisf & 0.826 & 0.589 \\
nomat & 0.826 & 0.544 \\
ETHICS+INTEREST & 1.000 & 0.368 \\
ETHICS+readybarrier & 1.000 & 0.322 \\
INTEREST+readybarrier & 1.000 & 0.406 \\
ETHICS+INTEREST+satisf & 1.000 & 0.361 \\
ETHICS+INTEREST+readybarrier & 1.000 & 0.322 \\
ETHICS+INTEREST+nomat & 1.000 & 0.363 \\
\hline
\end{tabular}

(Conservative solution term, solution coverage 0.769; solution consistency 0.816 ; cases with $>0.5$ memberships in solution term: farmer 1 , farmer 3 , farmer 4 , and farmer 12)

As mentioned before, being in need of financial support is a basic and essential precondition for farmers who stated acceptance. Additional factors are having the necessary machinery for and possibility of storing the feedstock (pressed into bales and covered), process-oriented factors that are connected to procedural justice (relational trust or having a demonstration plant) and not preferring another solution to the "wetland problem". Farmers who preferred to accept the biomass plants stated that maintenance of the cultural landscape is important or very important. As reasons for the positive attitude towards the cultural landscape, the value of the cultural landscape for agricultural use and its value as a cultural heritage are mentioned by these farmers. One farm has 550 ha of arable land and grasslands. In this case, wetland meadow use consists of mowing and grazing. The second farm has 1250 ha arable land only, and wetland meadow use consists only of mowing because this farmer does not have grazing animals.

\section{Rejection cases: "type B" and "type C" farmers}

Using the QCA results and the additional qualitative statements of the farmers, the rejection cases can be divided into two groups. "Type B" farmers are labelled as opponents due to ethical concerns. "Type C" farmers are generally open-minded towards the technology but refuse due to other conditions. Before describing each type separately, QCA results encompassing both groups are provided. The foundation for grouping the rejection farmers is the analysis of conditions. The analysis of necessary and sufficient conditions can only be made for all rejection cases. No necessary conditions could be found because consistency values are below 0.75 (see Additional file 5). All conditions passed neither the consistency nor the coverage test. 
The result of the analysis of sufficient conditions is displayed in Table $5^{8}$.

All five assumptions in Table 5 contribute to unique coverage for the outcome "rejection". The displayed assumptions (considering all of them) can be reduced to the following intermediate solution term:

(Solution coverage 0.822 ; solution consistency 1.00)

Type B farmers

ethics $*$ interest $*$ readybarrier $*$ SATISF $*$ NOMAT

\section{"Type B" farmers: ethically concerned refusers}

"Type B" farmers have very strong ethical concerns about burning wetland material. The following quotation underlines this pathway (ethics*interest"readybarrier* SATISF*NOMAT):

"Thermal use of hay? Never! Hay is fodder! It must not be burnt! ... That really hurts me. This can only stem from farmers who do not have animals. ... I'm not interested in this technology at all." (farmer 18).

Additional conditions that influence rejection are farmers' preference for other solutions to the "wetland problem" and a lack of trust in regional actors. Using biomass from meadows as forage for suckler cows and better water management were perceived as adequate solutions.

"Meadows should be used for feeding animals.

Generally, the water regulation is currently bad. It is mismanagement on the part of the regional water association. And the conservationists do a bad job. This is also problematic for the species protection. We don't have storks anymore" (farmer 13).

All "Type B" farmers stated that the wetlands should be maintained because they are essential for agriculture, a part of their cultural heritage, and an important habitat for flora and fauna.

\section{"Type C" farmers: open-minded refusers}

"Type C" farmers ethically accept the technology but stated at least one restricting condition why they reject the innovation (ETHICS *[NOMAT+SATISF+

\footnotetext{
${ }^{8}$ The parsimonious solution term for rejection is "SATISF"NOMAT" (solution coverage 0.923 , solution consistency 0.900 ). The intermediate solution term for rejection that included easy counterfactuals is "interest + ETHICS*(SATISF + NOMAT $)+$ ETHICS*readybarrier*(SATISF + NOMAT)" (solution coverage 0.856, solution consistency 0.980 ).
}

READYBARRIER]). Farmers in this group each reported different restrictions regarding the implementation of a biomass plant (see Table 6).

A few "type C" farmers mentioned conditions for the use of wetlands' biomass:

“It is only OK if it doesn't bring the mere cultivation

\section{Type $C$ farmers \\ ETHICS $*($ READYBARRIER + SATISF + NOMAT $)$}

of energy crops and if there is sufficient feedstock available that can't be used for other purposes. Its use for animals has priority" (farmer 9).

Additional conditions that influence rejection by "type C" farmers are the lack of knowledge concerning airing expenses, perceived high operational costs, and difficulty of integrating the procedure into daily work on the farm. Like "type B" members, some "type C" farmers stated that better water management in the Spreewald region is needed (farmers 7-8 and 13-15). Furthermore, during the interview, farmers were asked about their willingness to supply feedstock instead of installing a plant. Four "type C" farmers stated that they would sell their feedstock to an operator of a biomass plant (farmers 2, 11, 14, and 15). Five farmers would neither provide their feedstock nor install a plant (farmers 6, 10, 13, 16, and 17). Regarding the characterisation of these farmers, the sizes of cultivated land varied from very small farms with approximately 5 ha to medium-sized farms with 800 to 1500 ha. Farm production orientation is mainly towards forage crops. The wetland meadow use consists only of mowing and grazing. Additionally, farmers in this group recognised the importance of maintaining wetlands.

\section{Discussion and further implications}

In this section, we discuss our results in relation to the literature about acceptability, bioenergy, and transition management to derive case-related and general implications.

Because acceptability decisions are often temporary, they can vary over time as a result of certain influences. Whether acceptability decisions will change in a positive direction (higher acceptance) or in a negative direction (less acceptance) depends on activities and interventions during the innovation process. This idea is what Hitzeroth and Megerle [32] call sensitive "turnaround moments". With the knowledge of why farmers accept or reject the innovations, innovation process can be steered 
Table 5 Analysis of sufficient conditions for rejection (y) (based on the Quine-McCluskey algorithms, without logical remainders, on basis of truth table in Additional file 6)

\begin{tabular}{|c|c|c|c|c|}
\hline Assumptions & Cases & Raw coverage & Unique coverage & Consistency \\
\hline ethics*interest*readybarrier*SATISFY*NOMAT & Farmers 13 and 17 & 0.203 & 0.163 & 1.000 \\
\hline ETHICS*interest*READYBARRIER*NOMAT & Farmers 6,10 , and 16 & 0.305 & 0.127 & 1.000 \\
\hline ETHICS*INTEREST*SATISF*nomat & Farmers 5,7 , and 14 & 0.228 & 0.152 & 1.000 \\
\hline ETHICS*INTEREST*satisf*NOMAT & Farmers 8 and 9 & 0.144 & 0.033 & 1.000 \\
\hline ETHICS*INTEREST**eadybarrier*NOMAT & Farmers 2, 9, 11, and 15 & 0.338 & 0.101 & 1.000 \\
\hline
\end{tabular}

Solution coverage 0.822 ; solution consistency 1.000

through introducing acceptance building measures. In the present case study, it is of special interest whether the implementation of biomass heating plants at the farm level is still a promising innovation pathway or whether a different path should be taken.

Our study revealed the following factors for rejecting biomass heating plants at the farm level: (a) ethical concerns, (b) satisfaction with the current oven, (c) low availability of feedstock on the farm, and (d) perceived low readiness of technology.

a) Ethical concerns are a strong barrier that implies that farmers categorically reject biomass plants as a solution to the rising abandonment of small-scale wetlands. The opinions of these farmers are established (fixed) and are difficult to change during the innovation process. Therefore, it is not reasonable to insist on their acceptance in the future. When ethical concerns and values will not be adequately addressed in the innovation process, conflicts may occur [40]. To avoid conflicts and manage disagreements, it is recommended to involve concerned actors continuously in the discussion and reflection about the overall aims of the innovation and a landscape development strategy (e.g. suitable solutions to maintaining the small-scale wetlands and the whole cultural landscape).

Table 6 Quotations illustrating ethical acceptance and restricting conditions of "type C" farmers

\begin{tabular}{ll}
\hline Restricting condition & Quotation \\
\hline NOMAT & "In my case, I don't have enough feedstock \\
on my farm for my own oven" (farmer 8). & "I don't need a new heating system. My \\
& current fuel-and-wood oven works very \\
& well" (farmer 2). \\
& "This technology is suitable to maintain \\
& wetland and supply local energy if \\
READYBARRIER & it's economically \\
& feasible. But I think the low readiness of \\
& this technology might cause a lot of costs \\
& and problems" (farmer 15).
\end{tabular}

These quotations stem from the interviews in which farmers could make detailed statements in addition to the standardised questionnaire
Moderate ethical concerns (such as those expressed by farmers who agreed with the use of landscape material for bioenergy under certain circumstances) advocate for a smart use or cascade use of such biomass $[41,42]$. Smart use includes prioritising the application of biomass. Biomass should be used first to feed animals and only second to produce bioenergy. For the latter use, only biomass with low nutritional value (called co-product) is used. An example of cascade use in our case study is to apply the ash (residues of gasification) onto the field. This procedure helps to close the local resource cycle. The aforementioned ethical concerns are somehow related to the food and fuel debate, which is commonly brought up in the context of biogas production in Germany [26]. In both cases, the preferred use of biomass is for food or, alternatively, feed. This issue is backed by the traditional farmers' self-conception as "producers of food" rather than "producers of energy". European studies from Poland and the Czech Republic revealed that farmers ethically favour food production over growing biomass for energy production [24, 43]. With focus on the landscape scale, Werling et al. [15] argue for multi-functional landscapes by growing perennial bioenergy plants on marginal plots to avoid conflicts with food production. Perennial bioenergy plants increase landscape diversity and support other ecosystem services [15].

b) If farmers are satisfied with their current heating system, it is very unlikely that they will implement a biomass plant on their own farms in the coming years. This finding does not necessarily imply that biomass plants are per se an inadequate solution to the "wetland problem". An alternative option could be shifting the implementation of biomass plants from the single-farm level (as we have done in the present analysis) to the community level. This shift in the innovation process is also a starting point for a "new" acceptability study.

c) The low availability of own feedstock was identified as another barrier to acceptance by farmers. This is in line with the statement of Scarlat et al. [42], who 
point out that the success of establishing bioenergy systems depends on (among other things) the availability of biomass. To overcome this barrier, a biomass plant at the community level could be a promising solution. Feedstock for a communitybased biomass plant can be jointly supplied by various farms from the region. In the interviews, some farmers stated that they would provide their feedstock for a regional biomass plant. One farmer even added that he would appreciate discussing with colleagues the option of jointly mapping suitable plots for producing feedstock.

d) Advances in technology are seen as a key issue in implementing effective and efficient bioenergy systems [42]. The gasification technology that is the basis of biomass heating production in the Spreewald case study is still relatively new. Due to the currently low readiness of this technology, more time for experimentation and technology development is needed. From a socio-technological perspective, additional constraints are the lack of financial support from the government, regulatory limitations (e.g. emission protection law), and the limited availability of the technology. These are typical challenges in socio-technological niches and their management $[44,45]$. To overcome such constraints and to create a "market niche", adequate funding schemes, new shared rules (e.g. revision of existing laws), and routines within the "sociotechnical regime" are required [44]. Generally, for single farmers and small companies, it is more difficult to apply for investment subsidies than it is for bigger entities. Therefore, it might be promising to install a biomass plant at the community level. Wolsink [16] and Cavicchi [46] point out that the present (bio) energy system, with its often hierarchical, top-down, large-scale, market-oriented, and lobby-oriented character, should be restructured. However, a rethinking of the current energy strategy is overdue. For instance, top-down pathways, such as installation of wind turbines in rural areas, can cause rejection by communities and even regional conflicts [16, 17]. Gailing and Röhring [47] propose pushing a change from a mere "installation site" management for renewable energy into collaborative "regional action areas" where local actors are engaged. This is in line with the concept of decentralised "micro-grid energy systems". Such micro-grid systems should be integrated into landscape planning and management that defines available and suitable space for renewable energy focuses in coproduction with all actors (including local residents) [16].
In addition to the already discussed influencing factors, our study revealed further factors that potentially support enhancing acceptance: (e) valorisation of wetlands by farmers and (f) trust and co-operation between actors (justice).

e) As the results show, all interviewed farmers stated that wetland meadows are worth maintaining because they are a pivotal part of the cultural landscape. Values of the cultural landscape are seen in its agricultural use, in its beauty, and in itself as a holder of cultural heritage and as a habitat for flora and fauna. This finding is in line with recent case studies. It is widespread that farmers place great meaning in the agricultural value of meadows [4]. Other studies point out that the cultural values of landscape (in general) are often appreciated by farmers, residents, and other regional actors [1, 24]. A survey of Polish farmers determined that most interviewed farmers preferred to conserve their cultural heritage than to exploit farmland exclusively for income from energy crops [24]. Our case study shows how both aims-bioenergy production and protection of cultural landscapes-can potentially be combined by implementing local biomass heating plants. The cultural values of the landscape that are shared by many local actors are a powerful social capital and a good starting point to jointly create a shared vision for cultural landscape protection $[1,48]$.

f) Our study shows that relational trust, procedural fairness, and justice play a role in proponents' ("type A" farmers') acceptability decisions. Relational trust is about truthfulness, mutual appreciation, and creating shared values among involved actors $[4,49$, 50]. The importance of these issues is revealed in a Scottish case study about landscape maintenance for grasslands with high nature values: The farmers' motivation was limited to cooperating in maintenance measures in case the relation between farmers and coordinators (conservationists is this case) was weak or unbalanced [4]. Regular contact; joint meetings on values, aims, conceptions, and solutions; and having a demonstration plant may help build trust [48]. Demonstration plants also foster technology development on a niche level and mutual and reflexive learning.

Finally, the influencing factor "need of financial support" as an essential precondition for acceptance has to be discussed. In the interviews, the farmers stated that an on-farm biomass plant requires a major investment. Farmers would need financial support from funding programmes for undertaking such investment. Applying for funding requires a lot of effort, and at the same time, the outcome of the application is 
uncertain. The investment costs can hardly be compensated by future income or energy price savings when producing energy from wetland biomass. The contribution of this bioenergy process chain to farmers' income is relatively low regardless of whether the energy is directly produced and used on-farm or the biomass is supplied to the market [7]. The profit margin in the biogas process chain is much higher if biogas and heat are used [7]. However, the biomass from the Spreewald wetlands is less favourable than other feedstocks for biogas production.

The discussion points above indicate how to integrate the results of the specific acceptability study in a wider context of landscape design and management. As we have shown, such integration builds on mutable acceptability decisions [41], reflexive and iterative learning processes (e.g. [44, 51, 52]), innovation system thinking with feedback loops [44, 48], and adaptive landscape design [48]. Reflecting results is always crucial because acceptability studies are often only a piece of the puzzle of a broader picture. Thus, this is not only important for the present case study; the results also have a general implication for cases with place-based innovations embedded in cultural landscapes. Especially considering that some studies neglect or underestimate such a process of temporal-spatial contextualisation [53, 54], this seems to be a valuable recommendation.

\section{Conclusion}

The paper analysed farmers' acceptability of local biomass heating plants in the Spreewald region (Germany) and its contribution to cultural landscape management. Fuzzy QCA was a suitable method for revealing complex patterns of acceptability and for identifying different farmer types regarding the attitudes towards biomass plants. Our analysis revealed that acceptance of biomass plants at the farm level is relatively low. Contextualising degrees of acceptability and their underlying factors supports revising and adapting the innovation pathway. For the Spreewald case study, a biomass plant at the community level seems to be a promising solution. However, the acceptability of such a community-based biomass plant and further conditions should be investigated before implementing this idea. This finding directly indicates the importance of integrating each acceptability study into a broader picture. For this purpose, we propose integrating acceptability studies into an adaptive landscape design, if appropriate. To refine such an integration procedure, further research is needed by applying the procedure to additional cases and other contexts. In conclusion, our paper provides a scientific contribution in two ways. First, knowledge has been gained regarding how a local biomass plant can help reduce land abandonment in cultural landscapes with small-scale meadows. Second, we advanced the state of the art in acceptability studies.

\section{Additional files}

Additional file 1: List of interviews table. (DOCX $24 \mathrm{~kb}$ )

Additional file 2: Questionnaire for interviewing farmers regarding their acceptance of local heating plants. (PDF $96 \mathrm{~kb}$ )

Additional file 3: READY-BARRIER" (the mean of variable "interest in technology" and "perceived readiness" including also relevant qualitative statements). (DOCX $24 \mathrm{~kb}$ )

Additional file 4: Truth table for positive outcome (= acceptance) without logical remainders. (DOCX $25 \mathrm{~kb}$ )

Additional file 5: Analysis of Necessary Conditions for negative outcome (=rejection). (DOCX $24 \mathrm{~kb}$ )

Additional file 6: Truth table for negative outcome (= rejection) without logical remainders. (DOCX 25 kb)

\section{Abbreviations}

DOI: Diffusion of innovation theory; fsQCA: Fuzzy set qualitative comparative analysis; QCA: Qualitative comparative analysis; SDGs: Sustainable Development Goals; TAM: Technology acceptance model

\section{Acknowledgements}

Not applicable.

\section{Authors' contributions}

MB devised the main conceptual ideas; collected, processed, and analysed the data; and wrote major parts of the paper. RS contributed to the methodological design, supervised the data collection, revised the manuscript, and made the suggestions for improvements. $\mathrm{NH}$ contributed to the case study description, revised the manuscript, and made the suggestions for improvement. NH gave feedback on the study design and data interpretation, and provided access to the interviewees. All authors read and approved the final manuscript.

Funding

Funding from the Federal Ministry of Education and Research, Germany (BMBF), has supported this study (funding code FKZ033L145D).

\section{Availability of data and materials}

The datasets generated and analysed during the current study are not publicly available due protecting confidentiality of sensitive information but are available from the corresponding author on reasonable request.

\section{Ethics approval and consent to participate}

Before interviews were conducted, an interview consent form was provided to all participants. Each participant signed a consent letter in order to participate in the interview. Ethics approval is not applicable.

\section{Consent for publication}

The authors consent to publication.

\section{Competing interests}

The authors declare that they have no competing interests.

\section{Author details}

'Leibniz Centre for Agricultural Landscape Research (ZALF), Eberswalder Str. 84, 15374 Müncheberg, Germany. ${ }^{2}$ State Office for Environment of the Federal State of Brandenburg (LfU), Department for Large Nature Reserves and Regional Development, UNESCO Biosphere Reserve Spreewald, Schulstrasse 9, 03222 Lübbenau/Spreewald, Germany. 


\section{Received: 18 January 2019 Accepted: 17 July 2019}

\section{Published online: 10 September 2019}

\section{References}

1. Plieninger T, Bieling C, Ohnesorge B, Schaich H, Schleyer C, Wolff F (2013) Exploring futures of ecosystem services in cultural landscapes through participatory scenario development in the Swabian Alb, Germany. Ecol Soc 18. https://doi.org/10.5751/ES-05802-180339

2. Plieninger T, Höchtl F, Spek T (2006) Traditional land-use and nature conservation in European rural landscapes. Environ Sci Policy 9:317-321. https://doi.org/10.1016/j.envsci.2006.03.001

3. Schulp CJE, Levers C, Kuemmerle T, Tieskens KF, Verburg PH (2019) Mapping and modelling past and future land use change in Europe's cultural landscapes. Land Use Policy 80:332-344. https://doi.org/10.1016/j. landusepol.2018.04.030

4. McGinlay J, Gowing DJG, Budds J (2017) The threat of abandonment in socio-ecological landscapes: farmers' motivations and perspectives on high nature value grassland conservation. Environ Sci Policy 69:39-49. https://doi. org/10.1016/j.envsci.2016.12.007

5. Biggs R, Westley F, Carpenter S (2010) Navigating the Back Loop: Fostering social innovation and transformation in ecosystem management. Ecol Soc 15. https://doi.org/10.5751/ES-03411-150209

6. Grunwald A, Rösch C (2011) Sustainability assessment of energy technologies: towards an integrative framework. Energy Sustain Soc 1(3). https://doi.org/10.1186/2192-0567-1-3

7. Rösch C, Skarka J, Raab K, Stelzer V (2009) Energy production from grassland - assessing the sustainability of different process chains under German conditions. Biomass Bioenerg 33:689-700. https://doi.org/10.1016/j. biombioe.2008.10.008

8. Levers C, Schneider M, Prishchepov AV, Estel S, Kuemmerle T (2018) Spatial variation in determinants of agricultural land abandonment in Europe. Sci Total Environ 644:95-111. https://doi.org/10.1016/j.scitotenv.2018.06.326

9. van der Zanden EH, Verburg PH, Schulp CJE, Verkerk PJ (2017) Trade-offs of European agricultural abandonment. Land Use Policy 62:290-301. https:// doi.org/10.1016/j.landusepol.2017.01.003

10. Beilin $R$, Lindborg $R$, Stenseke $M$, Pereira HM, Llausàs $A$, Slätmo $E$, Cerqueira Y, Navarro L, Rodrigues P, Reichelt N, Munro N, Queiroz C (2014) Analysing how drivers of agricultural land abandonment affect biodiversity and cultural landscapes using case studies from Scandinavia, Iberia and Oceania. Land Use Policy 36:60-72. https://doi.org/10.1016/j.landusepol.2013.07.003

11. Dauber J, Miyake S (2016) To integrate or to segregate food crop and energy crop cultivation at the landscape scale? Perspectives on biodiversity conservation in agriculture in Europe. Energy Sustain Soc 6. https://doi.org/1 0.1186/s13705-016-0089-5

12. McGovern G, Klenke T (2018) Towards a driver framework for regional bioenergy pathways. J Clean Prod 185:610-618. https://doi.org/10.1016/j. jclepro.2018.02.251

13. INRENA, IEA, FAO (2017) Bioenergy for Sustainable Development. https:// www.ieabioenergy.com/publications/bioenergy-for-sustainabledevelopment. Accessed 24 Oct 2018.

14. Dale VH, Kline KL, Buford MA, Volk TA, Tattersall Smith C, Stupak I (2016) Incorporating bioenergy into sustainable landscape designs. Renew and Sust Energ Rev 56:1158-1171. https://doi.org/10.1016/j.rser.2015.12.038

15. Werling BP, Pennington D, Landis DA Biodiversity services and bioenergy landscapes. Extension Bulletin, Michigan State University 3164:1-12

16. Wolsink M (2018) Co-production in distributed generation: renewable energy and creating space for fitting infrastructure within landscapes. Landscape Res 43:542-561. https://doi.org/10.1080/01426397.2017.1358360

17. Becker S, Naumann M (2017) Energy democracy: mapping the debate on energy alternatives. Geogr Compass 11:e12321. https://doi.org/10.1111/ gec3.12321

18. Gawel E, Lehmann P, Korte K, Strunz S, Bovet J, Köck W, Massier P, Löschel A, Schober D, Ohlhorst D, Tews K, Schreurs M, Reeg M, Wassermann S (2014) The future of the energy transition in Germany. Energy Sustain Soc 4. https://doi.org/10.1186/s13705-014-0015-7

19. Arbolino R, De Simone L, Yigitcanlar T, loppolo G (2018) Facilitating solid biomass production planning: insights from a comparative analysis of Italian and German marginalized areas. J Clean Prod 181:819-828. https://doi.org/1 0.1016/j.jclepro.2018.01.154

20. Sahota S, Shah G, Ghosh P, Kapoor R, Sengupta S, Singh P, Vijay V, Sahay A, Vijay VK, Thakur IS (2018) Review of trends in biogas upgradation technologies and future perspectives. Bioresource Technol Rep 1:79-88. https://doi.org/10.1016/j.biteb.2018.01.002

21. Judex JW, Wellinger M, Ludwig C, Biollaz SMA (2012) Gasification of hay in a bench scale fluidised bed reactor with emphasis on the suitability for gas turbines. Biomass Bioenerg 46:739-749. https://doi.org/10.1016/j.biombioe.2012.06.006

22. Achinas S, Achinas V, Euverink GJW (2017) A technological overview of biogas production from biowaste. Engineering 3:299-307. https://doi.org/1 0.1016/J.ENG.2017.03.002

23. Townsend TJ, Sparkes DL, Ramsden SJ, Glithero NJ, Wilson P (2018) Wheat straw availability for bioenergy in England. Energ Policy 122:349-357. https://doi.org/10.1016/j.enpol.2018.07.053

24. Zyadin A, Natarajan K, Igliński B, Iglińska A, Kaczmarek A, Kajdanek J, Pappinen A, Pelkonen P (2017) Farmers' willingness to supply biomass for energy generation: evidence from South and Central Poland. Biofuels 8: 421-430. https://doi.org/10.1080/17597269.2016.1225647

25. Busse M, Siebert R (2018) Acceptance studies in the field of land use-a critical and systematic review to advance the conceptualization of acceptance and acceptability. Land Use Policy 76:235-245. https://doi.org/1 0.1016/j.landusepol.2018.05.016

26. Schumacher K, Schultmann F (2017) Local acceptance of biogas plants: a comparative study in the trinational upper Rhine region. Waste Biomass Valori 8:2393-2412. https://doi.org/10.1007/s12649-016-9802-z

27. Chin H-C, Choong W-W, Wan Alwi SR, Mohammed AH (2014) Issues of social acceptance on biofuel development. J Clean Prod 71:30-39. https:// doi.org/10.1016/j.jclepro.2013.12.060

28. Davis FD (1989) Perceived usefulness, perceived ease of use, and user acceptance of information technology. MIS Quarterly 13:319. https:/doi.org/10.2307/249008

29. Lyytinen K, Damsgaard J (2001) What's wrong with the diffusion of innovation theory? In: Ardis MA, Marcolin BL (eds) Diffusing software product and process innovations. Springer US, Boston, MA, pp 173-190

30. Mallett A (2007) Social acceptance of renewable energy innovations: the role of technology cooperation in urban Mexico. Energy Policy 35:27902798. https://doi.org/10.1016/j.enpol.2006.12.008

31. Wüstenhagen R, Wolsink M, Bürer MJ (2007) Social acceptance of renewable energy innovation: an introduction to the concept. Energy Policy 35:26832691. https://doi.org/10.1016/j.enpol.2006.12.001

32. Hitzeroth M, Megerle A (2013) Renewable energy projects: acceptance risks and their management. Renew Sust Energ 27:576-584

33. Kahma N, Matschoss K (2017) The rejection of innovations? Rethinking technology diffusion and the non-use of smart energy services in Finland. Energy Re Soc Sci 34:27-36. https://doi.org/10.1016/j.erss.2017.05.024

34. McKendry P (2002) Energy production from biomass (part 2): conversion technologies. Bioresource Technol 83:47-54. https://doi.org/10.1016/S09608524(01)00119-5

35. Patton MQ (2019) Qualitative research and evaluation methods. Integrating theory and practice, fourth edition. SAGE Publications Ltd, Thousand Oaks

36. Yin RK (2019) Case study research and applications, 6th edn. SAGE Publications Ltd, Los Angeles

37. Ragin CC (2000) Fuzzy-set social science. University of Chicago Press, Chicago

38. Schneider CQ, Wagemann C (2012) Set-theoretic methods for the social sciences: a guide to qualitative comparative analysis. Cambridge University Press, Cambridge

39. Meyer C, Chen C, Matzdorf B (2018) Qualitative comparative institutional analysis of environmental governance: implications from research on payments for ecosystem services. Ecosystem Services 34:169-180. https:// doi.org/10.1016/j.ecoser.2018.07.008

40. Gamborg C, Anker HT, Sandøe P (2014) Ethical and legal challenges in bioenergy governance: coping with value disagreement and regulatory complexity. Energ Policy 69:326-333. https://doi.org/10.1016/j.enpol.2014.02.013

41. Ganzevles J, Asveld L, Osseweijer P (2015) Extending bioenergy towards smart biomass use Issues of social acceptance at Park Cuijk, The Netherlands. Energ Sust Soc 5:22. https://doi.org/10.1186/s13705-015-0053-9

42. Scarlat N, Dallemand J-F, Monforti-Ferrario F, Nita V (2015) The role of biomass and bioenergy in a future bioeconomy: policies and facts. Environ Develop 15:3-34. https://doi.org/10.1016/j.envdev.2015.03.006

43. Frantál B, Prousek A (2016) It's not right, but we do it. Exploring why and how Czech farmers become renewable energy producers. Biomass Bioenerg 87:26-34. https://doi.org/10.1016/j.biombioe.2016.02.007

44. Schot J, Geels FW (2008) Strategic niche management and sustainable innovation journeys: theory, findings, research agenda, and policy. Techno Anal Strateg 20:537-554. https://doi.org/10.1080/09537320802292651 
45. Geels FW, Schot J (2007) Typology of sociotechnical transition pathways. Res Policy 36:399-417. https://doi.org/10.1016/j.respol.2007.01.003

46. Cavicchi B (2018) The burden of sustainability: limits to sustainable bioenergy development in Norway. Energ Policy 119:585-599. https://doi. org/10.1016/j.enpol.2018.05.015

47. Gailing L, Röhring A (2014) Was ist dezentral an der Energiewende? Infrastrukturen erneuerbarer Energien als Herausforderungen und Chancen für ländliche Räume. Raumforschung und Raumordnung 73:31-43

48. Campellone RM, Chouinard KM, Fisichelli NA, Gallo JA, Lujan JR, McCormick RJ, Miewald TA, Murry BA, John Pierce D, Shively DR (2018) The iCASS platform: nine principles for landscape conservation design. Landscape Urban Plan 176:64-74. https://doi.org/10.1016/j.landurbplan.2018.04.008

49. Eswarlal VK, Vasudevan G, Dey PK, Vasudevan P (2014) Role of community acceptance in sustainable bioenergy projects in India. Energ Policy 73:333343. https://doi.org/10.1016/j.enpol.2014.04.019

50. Gross C (2007) Community perspectives of wind energy in Australia: the application of a justice and community fairness framework to increase social acceptance. Energ Policy 35:2727-2736. https://doi.org/10.1016/j. enpol.2006.12.013

51. Moser SC (2016) Can science on transformation transform science? Lessons from co-design. Curr Opin Env Sust 20:106-115. https://doi.org/10.1016/j. cosust.2016.10.007

52. Pahl-Wostl C (2009) A conceptual framework for analysing adaptive capacity and multi-level learning processes in resource governance regimes. Global Environ Chang 19:354-365. https://doi.org/10.1016/j.gloenvcha.2009.06.001

53. Schroeder LA, Isselstein J, Chaplin S, Peel S (2013) Agri-environment schemes: farmers' acceptance and perception of potential 'Payment by Results' in grassland-A case study in England. Land Use Policy 32:134-144. https://doi.org/10.1016/j.landusepol.2012.10.009

54. Veidemane K, Nikodemus O (2015) Coherence between marine and land use planning: public attitudes to landscapes in the context of siting a wind park along the Latvian coast of the Baltic Sea. J Environ Plann Man 58:949975. https://doi.org/10.1080/09640568.2014.903167

\section{Publisher's Note}

Springer Nature remains neutral with regard to jurisdictional claims in published maps and institutional affiliations.

Ready to submit your research? Choose BMC and benefit from:

- fast, convenient online submission

- thorough peer review by experienced researchers in your field

- rapid publication on acceptance

- support for research data, including large and complex data types

- gold Open Access which fosters wider collaboration and increased citations

- maximum visibility for your research: over $100 \mathrm{M}$ website views per year

At $\mathrm{BMC}$, research is always in progress.

Learn more biomedcentral.com/submissions 